SMALL INTESTINE

\title{
Efficacy and tolerability of racecadotril in the treatment of cholera in adults: a double blind, randomised, controlled clinical trial
}

\author{
N H Alam, H Ashraf, W A Khan, M M Karim, G J Fuchs
}

Gut 2003;52:1419-1423

See end of article for authors' affiliations

.....................

Correspondence to: Dr N H Alam, Clinical Sciences Division,

ICDDR,B, GPO Box 128 Dhaka 1000, Bangladesh; nhalam@icddrb.org mailto:nhalam@icddrb.org

Accepted for publication 27 May 2003
Background: The enkephalins, endogenous opiate substances, act as neurotransmitters along the entire digestive tract where they elicit intestinal antisecretory activity without affecting intestinal transit time or motility. Racecadotril, through inhibition of enkephalinase, reinforces the physiological activity of endogenous enkephalins and, therefore, shows intestinal antisecretory activity.

Aim: We conducted the study to determine the role of racecadotril as an adjunct to the standard treatment of cholera in adults.

Methods: The study was a double blind, randomised, placebo controlled clinical trial involving 110 adult male cholera patients who received either racecadotril or placebo in addition to standard cholera treatment. The major outcome measures (stool output, oral rehydration solution (ORS) intake, requirements for unscheduled intravenous fluid infusion, and duration of diarrhoea) were compared between the groups.

Results: Of 110 patients enrolled, 54 received racecadotril and 56 received placebo. Admission clinical characteristics were comparable between the groups. There was no significant difference in (mean (SD)) total stool output (racecadotril v placebo $315(228)$ v $280(156) \mathrm{g} / \mathrm{kg}$ ), total ORS intake (390 (264) v 369 $(240) \mathrm{ml} / \mathrm{kg}$ ), or duration of diarrhoea (35 (15) $\vee 32$ (13) hours) between the groups. Clinical success, defined as resolution of diarrhoea within 72 hours of initiation of study intervention, was similar in both groups (racecadotril $v$ placebo $96 \%$ v $89 \%$ ). The number of patients receiving unscheduled intravenous infusions was not significantly different between the groups (racecadotril v placebo $22 \%$ v 14\%). No drug related adverse effect was noted.

Conclusion: The study demonstrated that racecadotril therapy, although found to be safe, does not provide additional benefit in the treatment of severe cholera in adults.
$\mathrm{C}$ holera is often a severe disease characterised by acute watery diarrhoea, vomiting, and dehydration. If not appropriately treated, the mortality rate may be as high as $50-80 \%{ }^{1}$ The primary cause of death in cholera is hypovolaemic shock due to severe dehydration. The mechanism of fluid loss in cholera involves the production of a Vibrio cholerae enterotoxin which stimulates cellular adenylate cyclase in small and large intestinal mucosa and increases the intraepithelial concentration of cyclic adenosine monophosphate (CAMP), resulting in electrolyte and water secretion..$^{2-5}$ In addition to a direct effect of the cholera toxin on the intestinal mucosa, recent observations have suggested that the enteric nervous system is also involved in intestinal water and electrolyte secretion in cholera through release of neurotransmitters. ${ }^{6-9}$ The treatment of cholera remains rehydration with intravenous fluids/ oral rehydration solution (ORS) together with antimicrobial agents effective against $V$ cholerae. ${ }^{10}{ }^{11}$ Antisecretory drugs that reduce the rate of fluid loss in cholera have been sought in order to decrease fluid loss, and also to reduce the need for intravenous fluids and the severity of disease. Several drugs have been shown to have antisecretory effect in experimental animal studies ${ }^{12-15}$ and some of these have been tested in patients. ${ }^{13-19}$ Although some have been shown to reduce stool volume, these are not suitable for practical use due to adverse effects, and some drugs showed either minimal or no benefit. ${ }^{20-24}$ To date, none of the antisecretory drugs has been recommended for the clinical management of cholera patients.
The enkephalins, endogenous opiate substances first discovered in 1975, play an important physiological role by acting as neurotransmitters, most notably along the digestive tract where they elicit intestinal antisecretory activity without affecting intestinal transit time or motility. ${ }^{22}$ After release, they are rapidly inactivated by enkephalinase, which is present throughout the gastrointestinal tract. Racecadotril (enkephalinase inhibitor) is a dipeptide with a single amide bond, developed from research into structure-activity relationships in the enkephalinase molecule. The active metabolite of racecadotril interacts specifically with the active site of enkephalinase to produce potent blockade of the enzyme. ${ }^{23}$ Racecadotril reinforces the physiological activity of endogenous enkephalins and shows intestinal antisecretory activity without affecting intestinal transit. ${ }^{22}$ The antisecretory mechanism involves activation of $\delta$ receptors leading to reduced secretion of water and electrolytes through reduction in intracellular CAMP. ${ }^{24}$ These antisecretory and antidiarrhoeal effects have been demonstrated in dogs with cholera toxin induced secretion ${ }^{25}$ and in rats and humans after cholera toxin administration. ${ }^{26}{ }^{27}$ Some clinical studies have demonstrated greater efficacy for racecadotril in acute diarrhoea (other than cholera) compared with placebo and loperamide ${ }^{28-30}$ through its antisecretory mechanism. Thus

Abbreviations: ORS, oral rehydration solution; cAMP, cyclic adenosine monophosphate; ITT, intention to treat. 
the aim of this study was to determine if racecadotril is useful as an adjunctive therapy to standard ORS and antibiotic treatment for cholera.

\section{METHODS}

\section{Study design}

This was a double blind, randomised, controlled clinical trial to evaluate the efficacy, safety, and tolerability of oral racecadotril in the treatment of acute $V$ cholerae diarrhoea in adults. The study was conducted at the Clinical Research and Services Centre (CRSC) of the International Centre for Diarrhoeal Disease Research Bangladesh (ICDDR,B): Centre for Health and Population Research, Dhaka, Bangladesh, between May 2000 and February 2001. The study was approved by the research review and ethics committees of the centre.

\section{Study subjects}

Patients eligible for the study were males (to facilitate separate collection of stool and urine), aged 15-55 years, with a history of watery diarrhoea of less than 24 hours' duration, presenting with signs of severe dehydration (sunken eyes, reduced skin turgor, lethargy, unable to drink, and absent/ uncountable radial pulse). Initial stool examinations by dark field microscopy were positive for $V$ cholerae and patients passed watery stools at a rate of $>5 \mathrm{ml} / \mathrm{kg} / \mathrm{h}$ during the 4-6 hour observation (screening) period (to include the most severe cases). Patients or legal guardians (when patients were unable to provide consent themselves due to altered consciousness) gave written informed consent for participation in the study. Those who had taken antidiarrhoeal or antimicrobial drugs, and those with concomitant illnesses requiring antibiotic treatment were not eligible for the study. Prior to randomisation in the study, all patients were rehydrated with intravenous fluids containing polyelectrolytes $\left(\mathrm{Na}^{+} 133 \mathrm{mmol} / \mathrm{l}, \mathrm{K}^{+} 13 \mathrm{mmol} / \mathrm{l}, \mathrm{Cl}^{-} 98 \mathrm{mmol} / \mathrm{l}\right.$, and acetate equivalent to $48 \mathrm{mmol} / \mathrm{l}$ bicarbonate) at a rate of $100 \mathrm{ml} / \mathrm{kg}$ over 4-6 hours, in addition to replacement of ongoing stool losses. ORS was also allowed as soon as the patient was able to drink.

\section{Randomisation}

Patients who completed rehydration (within the 4-6 hour observation period) and fulfilled the eligibility criteria were randomised to receive treatment with either capsules of racecadotril $100 \mathrm{mg}$ four hourly or look-alike capsules of placebo four hourly as a control for 72 hours or up to the time when the patients fulfilled the criteria of cessation of diarrhoea, whichever was shorter. The randomisation list was prepared by a data management company with a test to placebo ratio of $1: 1$ using permuted blocks of 8. Drugs (racecadotril and placebo) were supplied in sequentially numbered opaque sealed packets for individual patients (1-110), each containing four separate blister packs of six capsules each. The blisters were labelled as day 1, day 2, day 3 , and redosing (redosing was required if the patient vomited up the capsule within 20 minutes).

\section{Case management}

After initial enrolment of the patient, a clinical history and physical findings were recorded by one of the investigators and treatment provided according to routine hospital practice. Immediately after randomisation (following intravenous rehydration), maintenance oral hydration therapy was started with standard WHO ORS $\left(\mathrm{Na}^{+} 90, \mathrm{Cl}^{-} 80, \mathrm{~K}^{+} 20\right.$, citrate 10 , and glucose $111 \mathrm{mmol} / \mathrm{l})$. During maintenance, patients consumed ORS according to need, with a minimum volume equal to continued losses of watery or loose stools and vomit. All patients received doxycycline $300 \mathrm{mg}$ as a single dose within 20 minutes of randomisation. Food was offered according to hospital practice (breakfast at 7 am, lunch at 12 noon, and supper at $6 \mathrm{pm}$ ). Plain water was allowed as desired by the patients. Intravenous fluids were reinstituted in some patients where signs of severe dehydration recurred despite appropriate ORS therapy or where excessive vomiting prevented continued oral therapy.

Patients were placed in a "cholera cot" with a small central opening through which stools were collected in a bucket placed underneath the cot. All fluid intakes (intravenous, ORS, water) and outputs (stool, urine, and vomit) were measured, and vital signs and body weight were similarly recorded every four hours during the study. Stool weight was measured on an electronic scale with a precision of $\mathrm{lg}$ (Sartorius, Germany). Urine was separated in a urine collector and volume measured with a calibrated cylinder. The weight of vomit was measured by collection in a preweighed bowl by subtracting the weight of the bowl. ORS volumes and plain water consumed by patients were measured by a calibrated cylinder. Body weight was measured on admission (before intravenous rehydration), at randomisation (after intravenous rehydration), and every four hours until discharge, using the same electronic scale, which was calibrated daily using standard weights.

\section{Laboratory investigations}

Fresh stool samples were examined for the presence $V$ cholerae by dark field microscopy during the 4-6 hour observation period before randomisation. Stool samples were cultured

Table 1 Admission characteristics of all patients

\begin{tabular}{|c|c|c|}
\hline Variable & $\begin{array}{l}\text { Racecadotril } \\
(\mathrm{n}=54)\end{array}$ & $\begin{array}{l}\text { Placebo } \\
(n=56)\end{array}$ \\
\hline \multicolumn{3}{|l|}{ Age (y) } \\
\hline Mean & 28 & 29 \\
\hline Median (minimum, maximum) & $27(16,50)$ & $25,(15,45)$ \\
\hline \multicolumn{3}{|l|}{ Body weight $(\mathrm{kg})$} \\
\hline Mean & 44 & 43 \\
\hline Median (minimum, maximum) & $43(33,59)$ & $43(33,61)$ \\
\hline \multicolumn{3}{|l|}{ Body wt at randomisation $(\mathrm{kg})$} \\
\hline Mean & 49 & 48 \\
\hline Median (minimum, maximum) & $47(37,65)$ & $48(35,69)$ \\
\hline \multicolumn{3}{|c|}{ Duration of diarrhoea before adm (h) } \\
\hline Mean & 10 & 9 \\
\hline Median (minimum, maximum) & $8(4,23)$ & $8(3,19)$ \\
\hline \multicolumn{3}{|c|}{ No of watery stools before admission } \\
\hline Mean & 11 & 11 \\
\hline Median (minimum, maximum) & $10(3,30)$ & $10(4,30)$ \\
\hline \multicolumn{3}{|c|}{$\begin{array}{l}\text { Duration of vomiting before admission } \\
\text { (h) }\end{array}$} \\
\hline Mean & 7 & 6 \\
\hline Median (minimum, maximum) & $5(1,21)$ & $4(1,16)$ \\
\hline \multicolumn{3}{|l|}{ No of vomits before admission } \\
\hline Mean & 5 & 4 \\
\hline Median (minimum, maximum) & $5(0,12)$ & $4(1,12)$ \\
\hline \multirow{2}{*}{\multicolumn{3}{|c|}{$\begin{array}{l}\text { Screening period } \\
\text { Stool output }(\mathrm{g} / \mathrm{kg} / \mathrm{h})\end{array}$}} \\
\hline & & \\
\hline Mean & 15 & \\
\hline Median (minimum, maximum) & $13(5,34)$ & $14(5,30)$ \\
\hline \multicolumn{3}{|l|}{ No of watery stools } \\
\hline Mean & & \\
\hline Median (minimum, maximum) & $18(5,41)$ & $17(6,44)$ \\
\hline \multicolumn{3}{|l|}{ ORS intake $(\mathrm{ml} / \mathrm{kg})$} \\
\hline Mean & 47 & 50 \\
\hline \multirow{2}{*}{\multicolumn{3}{|c|}{ IV fluids $(\mathrm{ml} / \mathrm{kg})$}} \\
\hline & & \\
\hline Mean & 162 & \\
\hline Median (minimum, maximum) & $145(108,234)$ & $153(102,290)$ \\
\hline \multicolumn{3}{|l|}{ Water intake $(\mathrm{ml} / \mathrm{kg})$} \\
\hline Mean & 0.4 & 0.7 \\
\hline Median (minimum, maximum) & $0(0,25)$ & $0(0,20)$ \\
\hline
\end{tabular}

ORS, oral rehydration solution; IV, intravenous. 


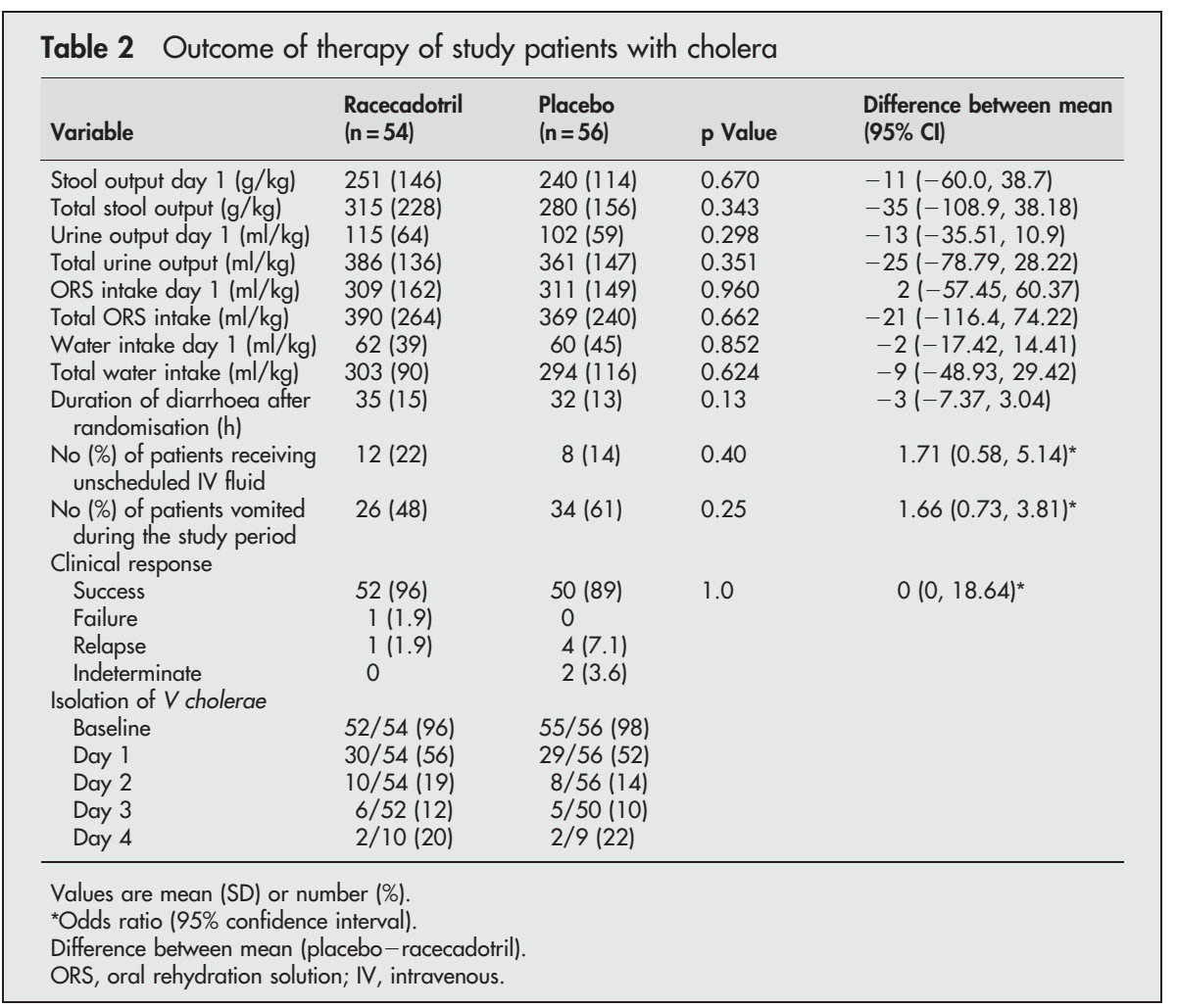

using standard techniques for isolation and identification of $V$ cholerae, Shigella, Salmonella, and Campylobacter at randomisation; thereafter, stool was cultured daily only for $V$ cholerae. Peripheral venous blood samples were tested for haematocrit, total and differential white blood cell counts, plasma specific gravity, blood urea nitrogen, creatinine, sodium, potassium, chloride, and bicarbonate at randomisation, at 24 hours from the time of randomisation, and at discharge. Abnormality in any test was followed until their resolution (tests were repeated daily).

All patients were observed closely until discharge (patients were discharged 24 hours after resolution of diarrhoea to observe signs of relapse). Resolution of diarrhoea was defined if patients did not have a stool for at last 12 hours or if they had two consecutive normal (formed) stools. Clinical success was defined as cessation of diarrhoea within 72 hours from the start of study medication, and those with continued watery stools for more than 72 hours were considered as clinical failures. Oral therapy failure was defined as reappearance of signs and/or symptoms of dehydration,

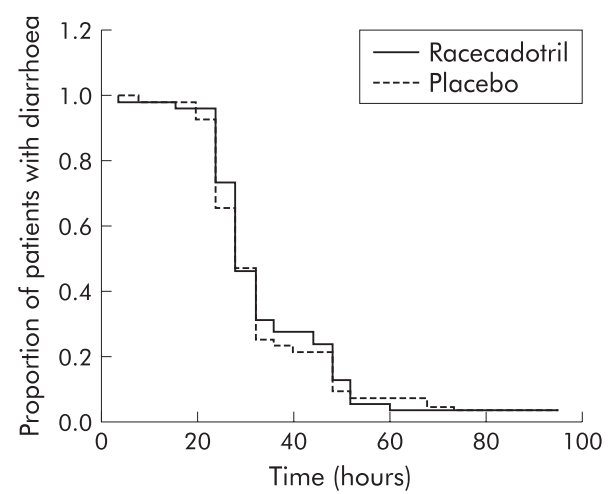

Figure 1 Survival plot for duration of diarrhoea in the racecadotril and placebo groups. requiring unscheduled intravenous fluid therapy. Assessment of clinical efficacy and adverse effects could not be ascertained if the patient was withdrawn before completion of 72 hours or discharge. Duration of diarrhoea (in hours) was calculated from the time of randomisation to the last watery stool. Clinical relapse was noted if the patient's diarrhoea resolved within 72 hours but watery stools reappeared in the subsequent 24 hour period.

\section{STATISTICAL METHODS}

\section{Sample size}

A total of 110 patients were enrolled to accrue 100 evaluable "intention to treat" (ITT) patients with cholera. Sample size was determined with an expectation of a 33\% reduction in total stool output with racecadotril compared with placebo, using a $5 \%$ level of significance and $80 \%$ power. The sample size calculation assumed a control mean total stool output of $273 \mathrm{~g} / \mathrm{kg}$ (SD 157). ${ }^{31}$

\section{Data analysis}

All statistical tests were performed using SPSS PC+ (version 10). All statistical tests were two tailed, performed at the $5 \%$ level of significance. Continuous variables were compared between groups using the Student's $t$ test and categorical variables were compared with the $\chi^{2}$ test or Fisher's exact test, as appropriate. The Mann-Whitney U test was also employed to compare continuous variables where appropriate. Kaplan-Meier survival curves were constructed for the duration of diarrhoea and were compared by log rank test. All analyses were performed on the ITT data set.

\section{RESULTS}

In total, 194 patients were screened for the study at the CRSC of ICDDR,B of whom 110 were randomised to treatment: 54 received racecadotril and 56 received placebo. The principal reasons for non-randomisation were patients being $V$ cholerae negative (81 patients) by dark field stool microscopy and refusal to participate in the study (three patients). All 
randomised patients were included in the efficacy and safety evaluations. One patient from the placebo group left the hospital against medical advice before resolution of diarrhoea and was excluded from the calculation of duration of diarrhoea, while the response to therapy was reported as indeterminate. Another patient, also from the placebo group, had resolution of diarrhoea but left before completion of the study, and response to therapy was also reported as indeterminate. Baseline clinical characteristics with regard to patient age, body weight, duration of diarrhoea, duration of vomiting, purging rate, and fluid intake during the screening period were comparable between the two groups (table 1). There were no statistically significant differences between the two treatments for the major outcome variables: stool output, ORS intake, and need for unscheduled intravenous fluids (table 2). The majority of patients had resolution of their diarrhoea within 72 hours (clinical success), and success rates were similar in both groups (racecadotril $v$ placebo $96 \% \vee 89 \%$ ). Mean duration of diarrhoea and bacterial clearance were similar in both groups (table 2). Kaplan-Meier survival curves (fig 1) for duration of diarrhoea were also similar in both groups $(p=0.7$, log rank test). Adverse experiences noted as per protocol such as vomiting, reappearance of dehydration, abdominal pain, headache, anorexia, etc., were not different between the treatment groups. No hypernatraemia (serum sodium $>150 \mathrm{mmol} / \mathrm{l}$ ) was observed at randomisation or discharge in either treatment group and one patient in the placebo group had mild hyponatraemia (serum sodium $<130 \mathrm{mmol} / \mathrm{l}$ ) at discharge.

\section{DISCUSSION}

The results of this study demonstrated that racecadotril therapy, as an adjunct to standard treatment of cholera, failed to show any additional benefit. It neither reduced the severity of illness by reducing stool output nor was there a reduction in duration of illness. The antisecretory activity of racecadotril previously demonstrated in animal models of secretory diarrhoea ${ }^{25}{ }^{26}$ was confirmed in a human model of secretory diarrhoea. ${ }^{27}$ In all of these preclinical studies, racecadotril was given prior to introduction of cholera toxin. In our clinical trial, racecadotril treatment was started after the secretory process had been established due to cholera. Whether racecadotril is unable to reverse the secretory process of cholera could not be confirmed in this study.

Three well designed placebo controlled clinical studies ${ }^{32}{ }^{33}$ have shown that racecadotril is effective in enhancing recovery of acute diarrhoea in both children and adults. In the adult study, ${ }^{32}$ the severity of diarrhoea seemed to be mild and the causative agents were mostly unknown, although a few patients' stools were positive for enterotoxigenic Escherichia coli. This patient population is not comparable with our study patients (all of our patients were suffering from severe cholera). In both of the paediatric studies, ${ }^{33} 34$ racecadotril had convincingly been able to substantially reduce stool output (approximately 50\%) irrespective of the bacterial or viral aetiology of diarrhoea. Isolation of $V$ cholerae as a causative agent for diarrhoea was rare in these studies. Hence these patients also differed from ours.

The mechanism of antidiarrhoeal activity of racecadotril in diarrhoea caused by a virus is still unexplained. Further multicentre studies in non-cholera diarrhoea in adults and children might be useful to confirm the antidiarrhoeal activity of racecadotril and to establish its therapeutic application in acute watery diarrhoea other than severe cholera. Theoretically, the antisecretory effect of racecadotril should have reduced secretion and stool output in cholera. However, the results of our study failed to demonstrate such an effect. The likely explanations include: (a) inadequate absorption with lower than required tissue and/or serum concentrations of racecadotril due to short intestinal transit time; or (b) the effect is inadequate to offset the impact of a marked secretory process in severe cholera. However, our study was not designed to examine these possibilities. Before excluding racecadotril as an effective antisecretory drug in cholera, a similar study of parenteral racecadotril might be considered in the future.

Our study clearly demonstrated that current standard therapy for acute cholera diarrhoea in adults (doxycycline removing the infecting organism, $V$ cholerae, and ORS preventing continued dehydration) was highly effective. The onset of response and reduction in stool output was rapid, with stool normalisation occurring in a substantial proportion $(31 \%)$ of the study population within 24 hours. This is in contrast with the slower responses seen in patients with viral or other diarrhoeas ${ }^{35}$ where a specific and highly effective antibiotic is not available. Racecadotril under these circumstances does not have a role as adjunctive therapy, and indeed it is unlikely that any drug would have sufficient effect to substantially reduce the response times of current therapy. It remains a matter of speculation whether racecadotril would be beneficial in the absence of one (antimicrobial) of the two elements of standard therapy. Such a situation is unlikely to occur while effective antibiotics form part of standard therapy.

Racecadotril was well tolerated, and the incidence of adverse experiences was no higher than that with placebo. The side effect profile was similar to placebo, and no serious events related to study treatment were observed. Also, racecadotril did not interfere with bacterial clearance.

In conclusion, the study demonstrated that the onset of response and reduction in stool output was rapid, with stool normalisation occurring in a substantial proportion of the patients within 24 hours. Under these conditions, racecadotril therapy, although found to be safe, does not provide additional benefit in the treatment of severe diarrhoea due to Vibrio cholerae in adults.

\section{ACKNOWLEDGEMENT}

This study was conducted at the ICDDR,B: Centre for Health and Population Research, with the support of grant No 52607, dated 16 May 2000, from SmithKline Beecham. ICDDR,B acknowledges with gratitude the commitment of SmithKline Beecham to the Centre's research efforts.

\section{Authors' affiliations}

N H Alam, H Ashraf, W A Khan, M M Karim, G J Fuchs, Clinical Sciences Division, International Centre for Diarrhoeal Disease Research (ICDDR,B): Centre for Health and Population Research, Dhaka, Bangladesh

G J Fuchs, Clinical Sciences Division, International Centre for Diarrhoeal Disease Research (ICDDR,B): Centre for Health and Population Research, Dhaka, Bangladesh, and Department of Pediatrics, University of Arkansas for Medical Sciences, Little Rock, AR, USA

\section{REFERENCES}

1 Benenson AS. Cholera. In: Benenson AS, ed. Control of communicable diseases in man, 11 th edn. New York: American Public Health Association, 1970:52.

2 Carpenter CCJ, Sack RB, Feeley JC, et al. Site and characteristics of electrolyte loss and effect of intraluminal glucose in experimental canine cholera. J Clin Invest 1968;47:1210-20.

3 Banwell JG, Pierce NF, Mitra RC, et al. Intestinal fluid and electrolyte transport in human cholera. J Clin Invest 1970;49:183-95.

4 Powell DW, Berschneider HM, Lawson LD, et al. Regulation of water and ion movement in intestine. Ciba Found Symp 1985;112:14-33

5 Donowitz M, Binder HJ. Effect of enterotoxins of Vibrio cholerae, Escherichia coli, and Shigella dysenteriae type 1 on fluid and electrolyte transport in the colon. J Infect Dis 1976;134:135-43.

6 Cassuto J, Jodal M, Lundgren $O$. The effect of nicotinic acid and muscarinic receptor blockade on cholera toxin induced secretion in rats and cats. Acta Physiol Scand 1982;114:573-7. 
7 Eklund S, Cassuto J, Jodal M, et al. The involvement of enteric nervous system in the intestinal secretion evoked by cyclic adenosine 3, 5-monophosphate. Acta Physiol Scand 1984;120:11-16.

8 Cassuto $\mathrm{J}$, Jodal $M$, Tuttle $\mathrm{R}$, et al. On the role of intramural nerves in the pathogenesis of cholera toxin-induced intestinal secretion. Scand J Gastroenterol 1981;16:377-84.

9 Cassuto J, Fahrenkrug J, Jodal M, et al. Release of vasoactive intestinal polypeptide from the cat small intestine exposed to cholera toxin. Gut 1981;22:958-63.

10 World Health Organization. Diarrheal Diseases Control Programme. A manual for the treatment of acute diarrhea for use by physicians and other senior health workers. Geneva, Switzerland: World Health Organization, 1984.

11 World Health Organization. The rational use of drugs in the management of acute diarrhea in children. Geneva, Switzerland: World Health Organization, 1990.

12 Holmgren J, Lange S, Lonnroth I. Reversal of cyclic AMP-mediated intestinal secretion in mice by chlorpromazine. Gastroenterology 1978;75:1103-8.

13 Jacoby HI, Marshall CH. Antagonism of cholera enterotoxin by antiinflammatory agents in the rat. Nature 1972;235:163-5.

14 Lonnroth I, Holmgren J, Lange S. Chlorpromazine inhibits cholera toxininduced intestinal hypersecretion. Med Biol 1977;55(3):126-29.

15 Smith PL, Field M. In vitro antisecretory effects of trifluoperazine and other neuroleptics in rabbit and human small intestine. Gastroenterology 1980;78:1545-53

16 Rabbani GH, Butler T, Bardhan PK, et al. Reduction of fluid-loss in cholera by nicotinic acid: a randomised controlled trial. Lancet 1983;2:1439-42.

17 Islam A, Bardhan PK, Islam MR, et al. A randomized double blind trial of aspirin versus placebo in cholera and non-cholera diarrhea. Trop Geogr Med 1986;38:221-5.

18 Rabbani GH, Butler T. Indomethacin and chloroquine fail to inhibit fluid loss in cholera. Gastroenterology 1985:89:1035-7.

19 Rabbani GH, Bardhan PK, Butler T, et al. Reduction of fluid loss in cholera by nicotinic acid. Lancet 1983;2:1439-42.

20 Rabbani GH, Butler T, Knight J, et al. Randomized controlled trial of berberine sulphate therapy for diarrhea due to enterotoxigenic Escherichia coli and Vibrio cholerae. Infect Dis 1987; 155:979-84.

21 Molla AM, Gyr K, Bardhan PK, et al. Effect of intravenous somatostatin on stool output in diarrhea due to Vibrio cholerae. Gatroenterology 1984:87:845-7.
22 Farthing MJG. Introduction. Enkephalinase inhibition: a rational approach to antisecretory therapy for acute diarrhea, Aliment Pharmacol Ther 1999; 13(suppl 6): 1-2.

23 Llorens C, Gacel G, Swerts JP, et al. Rational design of enkephalinase inhibitors: substrate specificity of enkephalinase studies from inhibitory potency of various dipeptides. Biochem Biophys Res Commun 1980;96:1710-17.

24 Rachmilewitz D, Kermali F, Chorer M, et al. Effect of opiates on human colonic adenyl cyclase activity. Eur J Pharmacol 1983;93:163-73.

25 Primi MP, Bueno L, Baumer PH, et al. Racecadotril demonstrates intestinal antisecretory activity in vivo. Aliment Phermacol Ther 1999;13(suppl 6):3-7.

26 Marcais-Collado H, Uchida G, Costentin J, et al. Naloxone-reversible antidiarrhoeal effects of enkephalinase inhibitors. Eur J Pharmacol 1987; 144:125-32.

27 Hinterleitner TA, Petrisch W, Dimsty G, et al. Acetorphan prevents choleratoxin induced water and electrolyte secretion in the human jejunum. Eur J Gatroenterol Hepatol 1997;9:887-91.

28 Baumer PH, Danquechln-Dorval E, Bertrand J, et al. Effects of acetorphan, an enkephalinase inhibitor, on experimental and acute diarrhea. Gut 1992;33:753-758.

29 Roge J, Baumer PH, Berad H, et al. The enkephalinase inhibitor, acetorphan, in acute diarrhea: a double blind, controlled trial versus loperamide. Scand J Gastroenterol 1993;28:352-4.

30 Vetel M, Berard H, Fretault N, et al. Double-blind study of the efficacy and safety of acetorphan versus loperamide in the treatment of acute diarrhea in adults. Gastroenterology 1995; 108:A705.

31 Alam NH, Majumdar RN, Fuchs GJ, et al. Efficacy and safety of oral rehydration solution with reduced osmolarity in adults with cholera: a randomized double-blind clinical trial. Lancet 1999;354:269-99.

32 Hamza H, Khalifa Ben H, Baumer P, et al. Racecadotril versus placebo in the treatment of acute diarrhea in adults. Aliment Pharmacol Ther 1999;13(suppl 6):15-19.

33 Cezard JP, Duhamel JF, Meyer M, et al. Efficacy and tolerability of racecadotril in acute diarrhea in children. Gastroenterology $2001 ; 120: 799-805$.

34 Salazar-Lindo E, Santisteban-Ponce J, Chea-Woo E, et al. Racecadotril in the treatment of acute watery diarrhea in children. N Engl J Med 2000;343:463-7.

35 Alam NH, Meier R, Schneider H, et al. Partially hydrolysed guar gumsupplemented oral rehydration solution in the treatment of acute diarrhoea in children. JPGN 2000:31:503-7. 